\title{
Huellas de la Historia para la historia. Fuentes en la historia social argentina reciente \\ Traces of the History for History: Sources in Recent Argentina Social History
}

\author{
María José Ortiz Bergia \\ Universidad Nacional de Córdoba \\ Consejo Nacional de Investigaciones Científicas y Técnicas \\ ortizbergia.mj@gmail.com
}

\section{Resumen}

En las últimas décadas, la historiografía ha sido protagonista de una renovación metodológica que ha implicado una nueva definición y tratamiento del registro histórico y la adopción de nuevas tipologías de fuentes, como los testimonios orales, judiciales y audiovisuales. Este artículo pretende explorar el alcance de las novedades introducidas en la operación historiográfica, en ese contexto, así como su impacto en la historia social argentina contemporánea.

\section{Palabras clave}

Metodología, evidencia histórica, fuentes orales, audiovisuales y judiciales, historia social argentina.

\begin{abstract}
In the last decades, historiography has undergone a methodological renovation with a new definition and treatment of historical evidences, and new typologies of sources, such as oral, judicial and audiovisual testimonies. This article examines the scope of the novelties introduced in the historiography operation in that context, as well as their impact in contemporary Argentinian social history.
\end{abstract}

\section{Key Words}

Methodology, historical evidence, oral, audiovisual and judicial sources, Argentinian social history. 


\section{Introducción}

Desde la instauración de la democracia en el país, la historia social argentina ha sido protagonista de importantes cambios disciplinares con consecuencias profundas en el oficio de sus practicantes - en las formas de plantear los problemas, la conceptualización del tiempo y del espacio, la elección de los materiales empíricos, los procedimientos heurísticos que estos últimos imponen y la elaboración de explicaciones y síntesis históricas-. Este proceso de renovación intelectual no puede considerarse el resultado pasivo de la difusión e imitación de modelos internacionales, sino más bien, el producto de una serie de proyectos académicos fuertemente comprometidos en la discusión metodológica de la historia.

Un aspecto fácilmente discernible de esas novedades ha sido la reconsideración de lo que se define como registro histórico, lo que ha derivado en la adopción de nuevas tipologías de evidencias como los testimonios orales, judiciales y audiovisuales. La relevancia adquirida por estos materiales ha comenzado a cimentar verdaderas líneas de investigación y las novedades se manifiestan en la creación de revistas especializadas, la institucionalización de campos de estudios y la multiplicación constante de la oferta de libros y cursos. Indicadores de este fenómeno es la reciente conformación de nuevas organizaciones académicas tales como la Asociación Argentina de Estudios de Cine y el Audiovisual (2008), la Asociación de Historia Oral de la República Argentina (2004) y la Red Interdisciplinaria de Estudios sobre Historia Reciente. Asimismo, la aparición de publicaciones online como la revista CAIANA. Revista de historia del arte y cultura visual (2012), dependiente del Centro Argentino de Investigadores de Arte, la Revista de Fuentes y Archivos del CEH "Prof. Carlos S. A. Segreti" ${ }^{1}$ y Aletheia, ${ }^{2}$ son expresiones tangibles de una preocupación dentro de la disciplina por pensar estas cuestiones.

A tres décadas del despliegue de ese proceso, este trabajo apunta a reflexionar sobre la operación historiográfica, los alcances de las novedades introducidas y su impacto en la práctica disciplinar. Con esa intención, ahondamos en la manera en que las innovaciones en torno al registro histórico han transformado los proyectos interpretativos. Hacemos esto a través de dos estrategias. Por una parte, relevamos el corpus completo de la revista Entrepasados, desde comienzos de los años noventa hasta el inicio de la segunda década del siglo XXI, cuando la misma fue interrumpida. Revisamos la manera en que desde esta revista se promovieron nuevas prácticas heurísticas y medimos cuantitativamente la manera en que esa labor impactó en los trabajos editados a lo largo de esos años. Por otra parte, para tener una mirada más amplia sobre el efecto de las novedades introducidas, analizamos

\footnotetext{
${ }^{1}$ La revista REFA se inició en 2010 bajo la dirección de Aurora Ravina con la finalidad de visibilizar la producción y las fuentes en los ámbitos provinciales. Actualmente cuenta con siete números y dentro de los mismos se destacan las secciones “Fuentes” y “Archivos, Bibliotecas, Museos, Colecciones”.

${ }^{2}$ La misma es una "revista electrónica semestral sobre problemáticas de historia y memoria colectiva en torno al pasado reciente argentino y de las sociedades latinoamericanas, en sus aspectos sociales, económicos, políticos y culturales, editada por la Maestría en Historia y Memoria de la Facultad de Humanidades y Ciencias de la Educación de la Universidad Nacional de La Plata”, http://www.aletheia.fahce.unlp.edu.ar/Bienvenidos [consulta 15 de mayo, 2013].
} 
artículos de historia social argentina editados en revistas nacionales, entre 2005 y 2014, que incorporaron nuevos registros históricos, como los testimonios orales, audiovisuales y judiciales. ${ }^{3}$ A partir de los artículos seleccionados, intentamos dar cuenta de la relación existente entre los interrogantes del historiador, la tipología de materiales utilizados y los diseños heurísticos elaborados.

\section{La incertidumbre como identidad disciplinar: registro histórico y heurística}

Los debates sobre las evidencias empíricas en la construcción del conocimiento histórico, la especificidad de su estatuto y los procedimientos críticos de que son objeto han sido ejes neurálgicos de la discusión disciplinar durante los dos últimos siglos. ${ }^{4}$ Lejos de cualquier ortodoxia, este núcleo del oficio ha resultado extremadamente flexible y permeable a los virajes metodológicos y epistemológicos producidos en la historiografía y en las ciencias sociales en general. En este primer apartado nuestro interés reside justamente en pasar revista brevemente a las reflexiones producidas en torno a los vestigios que utilizan los historiadores en las últimas décadas.

Es posible afirmar que existe acuerdo respecto a que la lógica histórica, el discurso de la demostración específico de la disciplina, se organiza sobre dos cimientos, la teoría y la práctica empírica, pero adquiere cierta singularidad respecto al resto de las ciencias sociales. Los materiales de investigación modelan las oportunidades y establecen limitaciones al quehacer historiográfico. Marc Bloch afirmaría que "los exploradores del pasado no son hombres del todo libres. El pasado es su tirano. No les permite conocer de él sino lo que él mismo les proporciona [conscientemente o no]". ${ }^{5}$ Los historiadores solo acceden al pasado a través de indicios, huellas y marcas dejadas sobre los objetos y en la memoria, no pueden inventarse materiales allí donde no han sido producidos y tampoco pueden preparar laboratorios para la experimentación. ${ }^{6}$ Sus evidencias tienen propiedades específicas y no todos los interrogantes que se le hagan son los apropiados, dado que “[M]ientras que puede proponerse cualquier teoría del proceso histórico, todas las teorías que no están conformes con las determinaciones de los datos empíricos son falsas”. 7

Más allá de esos principios más bien consensuados podemos aseverar que, en las últimas décadas del siglo XX, se han producido verdaderas transformaciones en la conceptualización, crítica y usos del registro histórico. Esto es inteligible en el marco de las modificaciones introducidas en la disciplina por el impacto del giro cultural y del giro

\footnotetext{
${ }^{3}$ Para construir nuestro corpus seleccionamos artículos de publicaciones periódicas nacionales destinadas a la historia general en los últimos diez años, como Anuario IEHS, Anuario de Rosario, Quinto Sol, Revista del ISHR, Trabajos y Comunicaciones, Población y Sociedad, Boletín del Instituto Ravignani y Anuario del CEH. Estas revistas fueron elegidas por constituir foros en los que los trabajos de historia social tienen amplia difusión y cuentan a su vez con versiones online que facilitaron su consulta.

${ }^{4}$ Natalie Zemon Davies, “¿Quién es el dueño de la historia? La profesión del historiador”, Entrepasados, 14 (1998): 111-8 (111).

${ }^{5}$ Marc Bloch, Apología para la historia o el oficio del historiador (México: FCE, 1996), 167.

${ }^{6}$ Carlo Ginzburg, Tentativas (Rosario: Prohistoria, 2004), 69-113.

${ }^{7}$ Edward P. Thompson, Miseria de la teoría (Barcelona: Editorial Crítica, 1981), 69.
} 
lingüístico, que expandieron la gama de objetos de estudio, propusieron nuevas inquietudes epistemológicas respecto a la lógica de demostración de la historia y generaron la emergencia de innovaciones metodológicas.

El mismo concepto de "fuente" ha sido objeto de controversia en la medida en que la utilización de ese término supone asumir una relación directa y transparente entre los registros con los que se trabaja y la realidad temporal que se investiga. Como alternativa más adecuada, se insiste en redefinir los materiales historiográficos como "vestigios", etiqueta destinada a capturar el carácter indirecto, accidental y azaroso de su permanencia y utilización. $^{8}$ En otras palabras, se destaca la necesidad de eludir un realismo ingenuo que adopta los materiales del historiador como fiel reflejo del devenir temporal de las sociedades y que pondera su objetividad como criterio de cientificidad.

Las impugnaciones también afirman el carácter socialmente construido de las huellas del pasado y cómo estas registran las relaciones de poder que atraviesan a la sociedad. Esto implica reconocer las limitadas posibilidades de acceso a las experiencias pasadas de ciertos grupos e individuos, dado su desigual acceso al registro histórico, como en el caso de las mujeres, los niños y los sectores subalternos en su conjunto. De ese modo, como una expresión de estos desajustes, la historia de las mujeres y los estudios de género han propuesto deconstruir la desigualdad existente en la conformación misma de los archivos, repensando las categorías de sentido desde las cuales fueron organizados. Esto incentiva:

[U]na escritura de la historia que no esté a su vez viciada por esa circunstancia reductora -que además falsifica-, debe tomar por el contrario en cuenta la presencia perenne de esas relaciones de poder basadas en la diferencia sexual, y que se hallan inscritas ya tanto en la producción como en la conservación de la evidencia. Las mismas relaciones que construyen el hecho social y cultural de la diferencia gobiernan las huellas y los rastros. ${ }^{9}$

Una crítica al carácter objetivo de los mismos archivos históricos, en la que se destaca no solo el azar y la fatalidad en el resguardo de la documentación, sino también la incidencia de las estructuras de poder en su conformación y conservación.

Dentro de este contexto, los historiadores se han tornado más escépticos respecto a la labor de los guardianes de la memoria, los archiveros, y han puesto en discusión la incidencia de sus esquemas conceptuales en la clasificación, ordenación, selección y expurgo de los rastros del pasado:

[...] los archivos tienen su propia historia, incrustada en los procesos que los crearon, en las normas y prácticas que gobiernan su administración, y en las decisiones acumuladas que han

\footnotetext{
${ }^{8}$ Peter Burke, Visto y no visto. El uso de la imagen como documento (España: Biblioteca de Bolsillo, 2005), 16.

${ }^{9}$ Elena Hernández Sandoica, “Joan Scott y la historiografía actual”, en Cristina Borderías (ed.), Joan Scott y las políticas de la Historia (Barcelona: Icaria Editorial, 2006), 259-81 (268).
}

ISSN 2174-4289 
conformado su material. Los archiveros son tanto los autores de lo que conservan como sus conservadores. ${ }^{10}$

Ahora bien, esta impugnación de la certidumbre objetivista de los historiadores que descansaba en el uso de sus materiales no implica pesimismo respecto de las posibilidades analíticas de la disciplina, sino un reconocimiento de sus particularidades, un incentivo a renovar y ampliar los procedimientos críticos, y una oportunidad para capitalizar la textura subjetiva de los materiales historiográficos. Como señalaba Carlo Gizburg "El hecho (de) que una fuente no sea 'objetiva' [...] no significa que sea inutilizable”. ${ }^{11}$ La misma puede instituirse como una vía de ingreso en las representaciones y las vivencias de una sociedad.

Las modificaciones producidas también están estrechamente vinculadas con la renovación de los objetos de estudio a partir del reconocimiento del carácter social y culturalmente construido de muchas realidades previamente esencializadas, fijas e inmutables. La historización de la sexualidad, el género, las emociones y el ambiente, han propiciado un ensanchamiento de las fronteras de la investigación histórica y la búsqueda de elementos que permitan el conocimiento de sus cambios y continuidades a lo largo del tiempo. En estos nuevos campos de estudio, los historiadores propusieron realizar una lectura a "contrapelo" de las fuentes tradicionales, pero en especial impulsaron la introducción de nuevos materiales de trabajo que proporcionaran una aproximación a dimensiones y actores del mundo social poco representados en las fuentes más habituales. ${ }^{12}$

En definitiva, somos testigos de que la multiplicación de los objetos de estudio y la crítica epistemológica a la actitud de los historiadores respecto a las "fuentes" del pasado han tenido un impacto notable en la ampliación significativa de lo que se considera registro histórico y en el tratamiento del mismo.

\section{La historiografía argentina}

En lo que hace a la historiografía argentina, desde los años ochenta y comienzos de los noventa se desplegó un intenso programa de renovación metodológica que sustentó cambios sustantivos en la práctica y en la enseñanza de la historia. Este fenómeno ha tenido proyecciones amplias en la reforma de los planes de estudio universitarios, la apertura de ofertas de posgrados, la creación de nuevos circuitos de discusión académica y la generación de un floreciente mercado editorial. La intención de este apartado es visibilizar las modalidades en las que se desplegó esa activa renovación de la práctica disciplinar y ahondar en uno de los mecanismos a través de los que fue difundida, las políticas

\footnotetext{
${ }^{10}$ Geoff Eley, Una línea torcida. De la historia cultural a la historia de la sociedad (Valencia: Universitat de Valéncia, 2008), 250.

${ }^{11}$ Carlo Ginzburg, El queso y los gusanos. El cosmos según un molinero del siglo XVI (Barcelona: Océano, 2011), 15.

${ }^{12}$ Para una revisión de algunas innovaciones producidas en el contexto historiográfico de las últimas décadas del siglo XX, véase Peter Burke, Formas de hacer Historia (Madrid: Alianza Universidad, 1996); Elena Hernández Sandoica, Tendencias historiográficas actuales. Escribir la historia hoy (Madrid: Akal, 2004).
} 
editoriales. Para acometer esta tarea exploramos una publicación semestral impulsada en esa época, Entrepasados.

En el panorama historiográfico argentino, podemos incluir a Entrepasados dentro de un conjunto de iniciativas editoriales que, entre los años ochenta y comienzos de los noventa, llevaron a cabo un esfuerzo sostenido dirigido a profesionalizar y modernizar los estudios históricos luego de la última dictadura militar. Este proyecto editorial fue contemporáneo de otras iniciativas similares como el Anuario de Rosario (1985), Anuario del IEHS (1986), el Boletín del Instituto Ravignani (1989) y Estudios Sociales (1991). Sin embargo, Entrepasados se distinguió del resto por su intención explícita de difundir las novedades historiográficas que se estaban produciendo. Y de tal modo, durante cerca de dos décadas (1991-2009), sus páginas fueran uno de los termómetros más sensibles de la adopción de innovaciones metodológicas en la historia social argentina.

En su primer número (1991), su comité editorial afirmaba que la revista estaba destinada a divulgar los resultados de las investigaciones que se estaban realizando desde enfoques renovadores y a conformar una plataforma con la que fomentar la revisión crítica de las condiciones de producción del conocimiento histórico. En palabras de los editores, la revista quería instituirse en un "lugar desde donde fomentar 'la batalla de las ideas' y redefinir el saber académico evitando las compartimentaciones y el provincialismo al que somos tan afectos”. ${ }^{13}$ Con esa perspectiva fue diseñada su política de secciones, privilegiando los espacios que favorecieran la reflexión crítica y la actualización disciplinar. Entre ellas figuraban “Artículos”, “Galería de Textos”, “Historia y Educación”, "Entrevista”, “En debate”, "Fuentes de Archivos”, y “Reseña de Libros”.

Desde su primer número, la sección "Fuentes de Archivos" tuvo la finalidad de describir y visibilizar repositorios y materiales poco utilizados previamente. ${ }^{14}$ En los primeros trabajos incluidos en esta sección, no solo se realizaron descripciones de los materiales disponibles en diferentes repositorios, sino también reflexiones metodológicas más amplias destinadas a propiciar el uso de registros poco abordados dentro de diversos campos de estudio. Así, en su primer número, Mirta Lobato y Fernando Rocchi destacaban que la tendencia de la historia económica a privilegiar los materiales susceptibles de altos niveles de agregación había generado la renuncia al estudio de problemas y períodos para los que no se disponía de ese tipo de materiales. En contraposición proponían la exploración de nuevos materiales que proporcionaran aproximaciones cualitativas a la historia de las empresas y los trabajadores, como los archivos de empresa. Los historiadores aseveraban que a partir de la utilización de esos registros, en general en manos privadas, podían inaugurarse innovadoras perspectivas de trabajo. ${ }^{15}$ En línea con esta colaboración, en el segundo número, Ema Cibotti dedicaba su contribución a los archivos sobre la inmigración y a la necesidad de combinar vestigios de diversas procedencias y

\footnotetext{
13 “¿Por qué Entrepasados?”, Entrepasados, 1 (1991): 3-4 (3).

${ }^{14}$ Ibid., 4.

15 Mirta Zaida Lobato y Fernando Rocchi, “Industria y trabajo: el valor de los archivos como fuente documental”, Entrepasados, 1 (1991): 131-41 (137).
} 
características como los testimonios orales, la correspondencia personal y las fotografías. Reconocía la necesidad de que los historiadores adquirieran un conjunto de conocimientos teórico-metodológicos específicos para el trabajo con ese tipo de documentación, que demandaba complejos mecanismos de decodificación. ${ }^{16}$ Una lógica similar tuvo el artículo redactado por Enrique Masés pocos años después, dedicado a explorar los expedientes judiciales. En su colaboración, el autor destacaba que muchas de las nuevas temáticas inauguradas dentro del proyecto de historia social de la Universidad Nacional del Comahue -la historia del peronismo, la arquitectura ciudadana y la historia del delito- habían sido posibles mediante la exploración del Archivo de la Justicia Letrada del Neuquén. Este último había proporcionado la oportunidad de abordar una historia “desde abajo" de las condiciones de vida y producción del territorio neuquino. ${ }^{17}$

Es necesario señalar que, en sus primeros años de desenvolvimiento, las iniciativas tendientes a propiciar debates disciplinares sobre la evidencia histórica no se agotaron en la sección de "Fuentes de Archivos", puesto que otras partes de la publicación también funcionaron como plataformas de difusión de estas novedades. Varios dosieres temáticos incluyeron traducciones de trabajos de reflexión metodológica, entrevistas a autores consagrados y artículos de investigaciones nacionales modélicas.

El primer dosier dedicado a las novedades introducidas en materia de registro histórico apareció en 1995 y estuvo destinado a la historia oral. La ocasión fue elegida por su coincidencia con el II Encuentro Nacional de Historia Oral, en un contexto en el que el campo historiográfico nacional estaba dando sus primeros pasos en este tipo de estrategias metodológicas. Al respecto, puede resultar interesante constatar que solo unos años antes había sido publicado el texto clásico de Dora Schwarzstein destinado a compilar a algunos de los referentes internacionales más importantes del campo. ${ }^{18}$ En consecuencia, la historia oral como metodología de trabajo había comenzado a ser utilizada más sistemáticamente en los años ochenta, pero aún estaba escasamente institucionalizada en el ámbito historiográfico nacional. En ese número de Entrepasados, dedicado a la historia oral, fueron incluidos diferentes elementos como una entrevista a Paul Thompson efectuada por Daniel James, una nota sobre el estado de la historia oral en el país a cargo de Dora Schwarztein y tres artículos de investigadores latinoamericanistas que trabajaban con testimonios orales (Ann Farnsworth-Alvear, Gould Jeffrey L. y Daniel James). ${ }^{19}$ La

\footnotetext{
${ }^{16}$ Ema Cibotti, “Los archivos de la inmigración”, Entrepasados, 2 (1992): 143-55.

${ }^{17}$ Enrique Masés, "Entre historiadores y anticuarios. Acerca del proyecto de recuperación, protección y clasificación del Archivo de la Justifica Letrada del Territorio Nacional de Neuquén”, Entrepasados, 7 (1994): 169-74; Enrique Masés, "1990-2000-Grupo de Estudios de Historia Social (GEHiSo). Una década de historia social en la Patagonia”, Entrepasados, 20/21 (2001): 211-3. La labor del grupo de historia social de la Universidad del Comahue ha sido sostenida a lo largo del tiempo y sigue incentivando aproximaciones a la historia social y política de la región a partir de la utilización de fuentes judiciales. Lisandro Gallucci, "La aparición de los desconocidos. Reflexiones a partir de una experiencia de investigación en la norpatagonia", Anuario, 22 (2010): 29-66. Este autor también ha realizado una reflexión semejante en "Las fuentes judiciales y el estudio de los sectores subalternos. Desafíos y posibilidades de su relación en la investigación historiográfica”, REFA, 1 (2010), http://www.refa.org.ar/revista-1.php [consulta 13 de marzo, 2015].

${ }^{18}$ Dora Schwarzstein, La Historia Oral (Buenos Aires: CEAL, 1991).

${ }^{19}$ Entrepasados, 9 (1995).
}

ISSN 2174-4289 
confección del dosier mostraba entonces un especial cuidado en introducir diferentes referentes destacados del campo a escala nacional e internacional. Esas distintas contribuciones hacían un recorrido por las posibilidades analíticas de la historia oral, desde su uso como fuente de información fáctica, predominante hasta esa fecha, hasta las preocupaciones más recientes por la memoria y la discusión respecto al testimonio oral como construcción cultural. Además, en el dosier emergían reflexiones más extensas sobre el rol del historiador, sus relaciones con los testigos y la elaboración del relato oral.

El uso de imágenes obtuvo una atención más constante dentro de la revista con la finalidad de estimular "la difusión y el uso de estos documentos parias". ${ }^{20}$ Tres números fueron dedicados a las imágenes en diversos formatos. El primer dosier tuvo como temática el cine y, a diferencia de las que sobrevinieron posteriormente, se dedicó a debatir en torno a aquel como forma de representación del pasado. Así pues, con una estructura muy similar al dosier dedicado a la historia oral, en el número temático de 1998 se incluyeron sendas entrevistas de Mario Ranaletti a dos referentes de las relaciones entre cine e historia, Marc Ferro y Robert Rosenstone. ${ }^{21}$ Además, se incluyó un artículo de Geoff Eley y Atina Grossmann sobre la película La Lista de Schlindler. ${ }^{22}$

Nuevamente, la revista centró su atención sobre estas temáticas en el año 2000 a través de un número que incluyó diversos trabajos dedicados a las imágenes como el cine, el teatro y la fotografía. La novedad de esa instancia fue la variedad de contribuciones reunidas sobre imágenes e historia argentina: cine, exposiciones, fotografía, pintura y filatelia. Pero la intencionalidad didáctica persistió y ese número se completó con una traducción de un ensayo de Raphael Samuel sobre fotografía y sendas entrevistas a Laura Mulvey y Luis Príamo sobre fotografía y cine. ${ }^{23}$ La inserción de entrevistas y traducciones de historiadores consagrados a nivel internacional constituyó una operación recurrente de Entrepasados tendiente a legitimar estas innovaciones metodológicas. Dos años después, nuevamente se dedicó un espacio al tratamiento de las "Imágenes en América Latina”, con la compilación de diferentes investigaciones sobre el uso de fotografías, prensa ilustrada y filmes. El dosier también incluía un artículo teórico-metodológico introductorio de Leticia Prislei, titulado "Fotografía y cine. La 'lectura de la imagen en perspectiva histórica'”. ${ }^{24}$ La mayoría de estos trabajos propiciaban la adopción de imágenes en la investigación histórica, rechazando su uso como mera ilustración -un añadido sin mayor valor explicativo- y destacando su condición de evidencias con un gran potencial heurístico. Para ello, enfatizaban la necesidad de eludir análisis ingenuos y proponían herramientas teóricometodológicas de diversa procedencia. Estas contribuciones resaltaban en general el peso de la autoría en la construcción de la mirada y las convenciones estéticas, culturas y sociales que modelan las composiciones visuales.

\footnotetext{
20 “El cine como fuente y reflexión para la investigación y la enseñanza de la historia”, Dosier en Entrepasados, 15 (1998), 92.

${ }^{21}$ Marc Ferro, Cine e Historia (Barcelona: Editorial Gustavo Gill, 1980); Robert A. Rosenstone, El pasado en imágenes. El desafío del cine a nuestra idea de la historia (Barcelona: Ariel, 1997).

${ }^{22}$ Entrepasados, 15 (1998).

${ }^{23}$ Entrepasados, 18/19 (2000).

${ }^{24}$ Entrepasados, 23 (2003).
}

ISSN 2174-4289 
Cada uno de los dosieres prestó especial consideración a la discusión teóricometodológica en el tratamiento de los registros históricos, en la elaboración de reflexiones críticas, balances y propuestas programáticas entre las que se destacaron los historiadores internacionales consagrados. En pocas palabras, parecía subyacer a dicha composición una intencionalidad didáctica destinada a facilitar la adopción de esas novedades por parte de los historiadores nacionales.

Pero, ¿cuál fue el impacto concreto de esas estrategias? Si bien resulta complicado medir la adopción de esos nuevos registros, la suma total de los trabajos de historia social argentina incluidos en Entrepasados que adoptaron evidencias como los testimonios orales, judiciales y audiovisuales puede resultar una aproximación valida a la cuestión. En consecuencia, podemos tener un número ilustrativo de este fenómeno si contabilizamos las contribuciones incluidas en la sección artículos y dosieres temáticos, entre 1991 y 2011, dedicados a objetos diversos de la historia argentina dentro del campo de la historia social. ${ }^{25}$ Dentro de esa selección pudimos advertir que los trabajos que adoptaron fuentes orales, judiciales, imágenes móviles y fijas -fotografías, pinturas, documentales, televisión y filmes de ficción-, y materiales gráficos pocos frecuentes en la historiografía previa, como manuales y revistas, fueron aproximadamente veintiséis a lo largo de la historia de la revista. Con 32 números en total, esto implica menos de un artículo por número. Pero estos guarismos ocultan variaciones temporales. Los trabajos que incluyeron este tipo de evidencias se distribuyeron en forma asimétrica y fueron incrementándose en los números editados en el nuevo siglo. ${ }^{26}$ Esa lenta incorporación de nuevos registros históricos testimonios orales, visuales y judiciales-, en los trabajos editados en la revista, permiten discernir que la adopción de esas innovaciones, si bien fue un fenómeno tangible, estuvo lejos de generalizarse. La iniciativa académica llevada a cabo por Entrepasados, si bien fue exitosa -aseguró la introducción en el campo historiográfico argentino de las modificaciones más globales que se estaban produciendo en la disciplina-, por mucho tiempo solo repercutió entre unos pocos.

\section{La historia social reciente}

Pero más que el análisis cuantitativo, lo que importan son las consecuencias interpretativas derivadas del tratamiento específico de este tipo de evidencias. En consecuencia, en el apartado anterior quedó pendiente la realización de reflexiones más extensas sobre las modalidades en que los historiadores argentinos comenzaron a utilizar esas fuentes. Entonces, con el propósito de realizar algunos avances en esa dirección hemos optado por analizar artículos de historia social argentina editados en los últimos diez años, que utilizan en forma predominante evidencias como los testimonios orales, audiovisuales y judiciales. A partir de los artículos seleccionados, intentamos responder a algunas preguntas

\footnotetext{
${ }^{25}$ El recorte sobre la problemática de la historia social argentina fue utilizado en un sentido bastante amplio, incluyendo algunas problemáticas que rozaban las prácticas, relaciones y representaciones sociales.

${ }^{26}$ De tal modo, de los 26 trabajos contabilizados, 8 fueron publicados dentro de los 17 números que se editaron entre 1991 y 2000, y 18 entre los 15 números que circularon entre 2001 y 2011.
}

ISSN 2174-4289 
relativas a la relación entre los problemas de investigación y el tratamiento de las fuentes utilizadas.

A partir de la época de entreguerras adquirió preeminencia la certidumbre de que toda buena historia era una "historia-problema" y que, en consecuencia, la tarea del historiador consistía en plantearse problemas que conformaban "el comienzo y el final de toda historia”. ${ }^{27}$ Esto supuso una verdadera novedad historiográfica al aseverar que la investigación se iniciaba con interrogantes que los historiadores imponían a sus fuentes y no viceversa, tal como había pregonado la historiografía decimonónica. Los investigadores no se acercaban a las fuentes carentes de conceptos e interrogantes, sino todo lo contrario, cargaban sobre sus hombros todo un conjunto de ideas previas que era necesario explicitar, sistematizar y definir para iniciar su actividad. La formulación de un interrogante, aunque nunca de una forma totalmente acabada, determinaba posteriormente el tipo, las características y la cantidad de materiales que eran necesarios para responder adecuadamente al cuestionario previamente definido. A lo largo del siglo XX, uno de los consensos construidos en torno al paradigma historiográfico fue por lo tanto la existencia de una relación de dependencia teórica entre el problema y las fuentes, que modelaba la percepción y la consulta de la evidencia.

Dentro de ese acuerdo metodológico, la ampliación de los interrogantes historiográficos hacia nuevas temáticas como la vida privada, las relaciones de género, los micro-conflictos y el ejercicio del poder tuvo como consecuencia el impulsar a los historiadores a ampliar el abanico de fuentes para la investigación, así como a desplegar nuevos postulados teórico-metodológicos que permitieran nuevas lecturas de fuentes tradicionales. Una de las estrategias articuladas fue la inflación de los repertorios con los cuales se construían los relatos históricos mediante la inclusión de fuentes audiovisuales, judiciales y orales. En este apartado, nos interesa preguntarnos por la relación existente entre esas fuentes y los interrogantes académicos.

Es posible reconocer que una de las principales prácticas que los historiadores sociales argentinos despliegan en torno a las fuentes audiovisuales, judiciales y orales, es aquella que se caracteriza por hacer uso de este tipo de materiales, pero no solo como evidencia, sino como objetos de conocimiento en sí mismos. Estrategia metodológica a la que denominamos fuente-evento y sobre la cual Jacques Le Goff construyó el binomio documento/monumento. ${ }^{28}$ Esto implica que la fuente se instituye simultáneamente en objeto y fuente de la investigación y, en consecuencia, los historiadores se interrogan por la forma y los contenidos de los materiales, las representaciones que han cristalizado y los intereses que expresan; también se cuestionan respecto a las condiciones de producción de la evidencia, el contexto, los actores intervinientes, los usos que se hicieron de la misma, su circulación y sus consecuencias históricas. Las fuentes no son definidas solo como una "mera representación de los eventos de la historia”, sino como "evento[s] de la historia”,

\footnotetext{
${ }^{27}$ Lucien Febvre, Combates por la historia (Barcelona: Planeta-Agostini, 1993), 23.

${ }^{28}$ Jacques Le Goff, El orden de la memoria. El tiempo como imaginario (Barcelona: Paidós, 1991), 275.
}

ISSN 2174-4289 
“algo que las personas hacen en el transcurso del tiempo y tiene efectos sobre los comportamientos colectivos e individuales". ${ }^{29}$

El interés por las fuentes como eventos está estrechamente ligada a los virajes historiográficos que destacan la importancia de las representaciones como elementos fundantes de la experiencia y la acción humana, el carácter subjetivo de las expresiones culturales y el reconocimiento de las estructuras de poder que circulan en la sociedad cristalizando posiciones asimétricas. ${ }^{30}$ Esto ha motivado la preocupación por comprender cómo se estructuran los discursos que modelan la vida social, cómo circulan, se transforman y se corporizan en prácticas sociales. Para ello, se han dispuesto esquemas de análisis centrados en la construcción de significados a través de la producción icónica, la memoria y el ejercicio de la justicia.

Entre quienes tratan con estas tipologías de evidencia, esta práctica de la fuenteevento resulta más habitual de lo que suele suponerse. Los estudios sobre cultura visual relevados se suelen construir a partir del estudio de películas y álbumes fotográficos, cuestionándose sobre cómo se forjaron sobre las mismas ciertas representaciones del mundo y qué efectos sociales tuvieron sobre la sociedad. Esto remite a la constatación de que las imágenes no constituyen simplemente un reflejo de la realidad, sino una construcción selectiva, el producto creativo y subjetivo de quien decidió que un evento, rostro o paisaje debía quedar registrado por la lente, la película o el dibujo. Esta perspectiva supone afirmar también que las imágenes han modelado los imaginarios colectivos, construido identidades sociopolíticas, proyectado discusiones públicas de diferente tenor y modelado la memoria colectiva de las sociedades. De tal modo, lo que interesa no es lo que la fuente muestra, sino la construcción misma del objeto y las formas en que circuló. Mariana Giordano y Alejandra Reyero (2008) ilustran bien esta agenda historiográfica construida alrededor de las imágenes:

\begin{abstract}
De este modo, y a través de un proceso de análisis e interpretación bajo la mirada de una “economía visual” que contemple aspectos tanto de su producción como de su circulación y consumo, consideramos la primera más allá de los individuos que las realizan, focalizando en las estrategias de representación que están presentes en la imagen fotográfica. En cuanto a la circulación, indagamos en los sistemas culturales y discursivos a través de los cuales las imágenes fotográficas se aprecian e interpretan, asignándoles un valor histórico, científico y estético. En cuanto al consumo o recepción, está referido tanto al hecho de preguntarnos para quién fue hecha esa imagen, quién la veía y quien la ve ahora, aspecto este último en el que nos incluimos como analistas. ${ }^{31}$
\end{abstract}

Algo similar se ha producido respecto a las fuentes judiciales. Alrededor de los registros que plasman la labor de jueces, abogados, policías y particulares, se han expandido los estudios sobre la justicia, ampliando las discusiones relativas a las

\footnotetext{
${ }^{29}$ Alessandro Portelli, “El uso de la entrevista en la historia oral”, Anuario, 20 (2003/2004): 35-48 (36).

${ }^{30}$ Roger Chartier, El mundo como representación. Estudios sobre historia cultural (Buenos Aires: Gedisa, 1992).

31 Mariana Giordano y Reyero Alejandra, “Mostrar y mostrarse. La construcción de memorias visuales e identidades étnicas desde los grupos hegemónicos chaqueños”, Entrepasados, 33 (2008): 71-93.
}

ISSN 2174-4289 
modalidades en que las personas -mujeres, subalternos, afro-descendientes, arrendatarios, indígenas y demás- hicieron uso de los estrados. ${ }^{32}$ Esto implica capitalizar el uso de fuentes judiciales en forma predominante para comprender la vida social que transcurrió alrededor del ejercicio de esa instancia política, y no necesariamente como una vía legítima de aproximación a otras dimensiones del mundo social. En otras palabras, las evidencias de la actividad judicial se utilizan en general como vías para acceder a la historia de la propia justicia, pasando por alto su potencial para proporcionar otro tipo de informaciones.

Estas aproximaciones hacia la fuente-evento se han revelado fuertemente productivas a la hora de comprender los discursos y su corporeización en prácticas concretas, las modalidades recursivas en que se crean y se recrean a través de la acción y la subjetividad humana. A pesar de esto, se han alzado algunas voces de alerta que destacan que esta modalidad de tratamiento de la evidencia resulta reduccionista, al restringir sus posibilidades analíticas a ciertos subcampos de conocimiento. Esto estaría mostrando ciertas limitaciones en la concepción de estos vestigios como fuentes para la historia, presentándose en cambio como "objetos de estudio que deben ser explicados". ${ }^{33}$ Esta crítica se relaciona con la posibilidad de abordar estos materiales como medios a partir de los cuales no solo dar cuenta de las representaciones del mundo y las prácticas sociales que las han generado, sino también de iluminar aspectos de la sociedad que fueron registrados en los documentos sin la intención de que así fuera. Dimensiones culturales, económicas, sociales y políticas de la vida privada y pública que no nos han dejado otros rastros.

Por otra parte, si ahondamos en la modalidad de trabajo con esas fuentes llama la atención cierta práctica recurrente en la manera de construir el corpus en el que se realiza una ponderación claramente asimétrica entre los criterios de variedad, cantidad y calidad de la documentación, con consecuencias importantes en la densidad y verosimilitud de las interpretaciones. En varias de las investigaciones analizadas las proposiciones se establecen a partir del estudio de una única tipología documental, en general elegida por su riqueza interna. Esta decisión metodológica, no obstante, implica eliminar la posibilidad de confrontar los materiales entre sí. A su vez, se contrapone a un consenso metodológico extendido dentro de la disciplina consistente en que la exhaustividad, como criterio en la selección documental, asegura miradas contrapuestas y complementarias sobre los procesos históricos. Desde esa perspectiva, el trabajo en profundidad de una sola tipología favorece la adherencia del investigador a los testimonios relevados, una confianza en su capacidad mimética para reflejar las prácticas sociales de los individuos.

\footnotetext{
32 Yolanda de Paz Trueba, “¿Madre hay una sola? La naturalización de la maternidad y los desvíos de la norma en el centro y el sur bonaerenses a fines del siglo XIX”, Entrepasados, 34 (2008): 95-110; María Paula Parolo, "Juicio, condena y ejecución de Francisco Acosta, 'Consentidor de ladrones'. Alcances y límites del poder de los comandantes de campaña en Tucumán a mediados del siglo XIX”, Anuario IEHS, 23 (2008): 175-98; Nicolás Rebagliati, "Negros y mulatos pobres en Buenos Aires (1786-1821)", Quinto Sol, vol. 18, 1 (2014), file:///C:/Users/Administrador/Downloads/834-2617-1-PB.pdf [consulta 9 de marzo, 2015]; Mariana Noce, "El poder y las mujeres. Los 'desarreglados' casos de Doña Rosa y de Doña Balbina", Anuario del CEH, 5 (2005): 127-51.

${ }^{33}$ Tomás Pérez Vejo, “¿Se puede escribir historia a partir de imágenes? El historiador y las fuentes icónicas”, Memoria Social, vol. 16, 32 (2012): 17-30 (18).
}

ISSN 2174-4289 
Otra tendencia relevada es aquella que se caracteriza por reducir los corpus en términos de unidades observacionales. Algunas investigaciones se limitan a solo una decena de imágenes, una película, algunos expedientes o testimonios orales. Esta reducción es justificada en la posibilidad que plantea a la hora de construir una metodología cualitativa e intensiva de los materiales bajo la lente del investigador.

En los trabajos elaborados a partir de archivos judiciales es recurrente este tipo de aproximaciones en las que a partir de un solo expediente o un grupo de ellos se intenta aprehender las prácticas legales de la población. Una expresión de esto son los usos de la justicia por los sectores subalternos, las mujeres u otros grupos sociales, para los cuales se utilizan unos pocos expedientes abordados en forma muy intensiva. Los investigadores demuestran una confianza muy grande respecto a las posibilidades de estos materiales para proporcionarles un acceso casi irrestricto a los sentidos construidos y a los intereses, las incertidumbres, los temores y las expectativas de los sujetos sociales. Este excesivo optimismo contrasta, empero, con las afirmaciones en donde a pie de página se reconoce que, la misma excepcionalidad que supone la judicialización de un hecho social incide en las posibilidades de generalizar las afirmaciones construidas a partir de ese tipo de vestigios.

La decisión de reducir el corpus documental en términos de cantidad y variedad de documentos tiene diversas consecuencias. La utilización de variados soportes y unidades observacionales constituye un criterio de positiva cautela epistemológica que expande las certezas elaboradas y sus posibles generalizaciones. Por otra parte, la reducción de la variedad y la cantidad de materiales limita las posibilidades interpretativas de las investigaciones así elaboradas, elimina las contradicciones y los matices que proporcionan las aproximaciones a un hecho social desde diferentes perspectivas; en otras palabras, conduce a una comprensión más unívoca de la realidad.

En pos de eludir estas limitaciones, quienes defienden una estrategia más "microhistórica" frente a los problemas sociales han elaborado un complejo modelo de explicación y verificación que busca tratar con el carácter excepcional de su documentación y de los hechos históricos que indaga. Para ello, se insiste en la necesidad de reconstruir intensamente los contextos en los que esos eventos se encuentran inscritos, el espacio próximo en el que "sucede un hecho, espacio concebido como el sistema de significados al que pertenece”. ${ }^{34}$ Los historiadores, al completar la información hipotética de sus fuentes excepcionales con inferencias que se desprenden del contexto en las que se encuentran insertas, llegan a alcanzar niveles aceptables de probabilidad. ${ }^{35}$

\footnotetext{
${ }^{34}$ Justo Serna y Anaclet Pons, Cómo se escribe la microhistoria: ensayo sobre Carlo Ginzburg (Madrid: Cátedra-Universitat de València, Frónesis, 2000).

${ }^{35}$ Carlo Ginzburg, El juez y el historiador: consideraciones al margen del proceso Sofri (Madrid: Anaya, 1993), 22.
} 
Esta modalidad de uso de las fuentes como evento se revierte en una segunda modalidad de trabajo con estos materiales, en donde los mismos son utilizados junto a otros testimonios de carácter muy variado y respecto de los cuales no mantienen relaciones de primacía. En este caso, los testimonios orales, judiciales y audiovisuales se introducen en la investigación histórica como medios a partir de los cuales elaborar respuestas desde un dispositivo plural, y no como objetos centrales de la investigación. Desde nuestra perspectiva, esta práctica metodológica puede adoptarse como un indicio efectivo de la ampliación de los cánones de construcción de corpus entre los historiadores argentinistas, en la medida en que estos nuevos materiales son revestidos del mismo estatus que las fuentes escritas más tradicionales del oficio historiográfico. En otras palabras, las fuentes judiciales, orales y audiovisuales no son exploradas como objetos de conocimiento en sí mismas, sino como vías por las cuales obtener información sobre distintos aspectos de la vida social. En estos casos, la heterogeneidad y la pluralidad son adoptadas intencionalmente como una posibilidad de alcanzar mayores niveles de veracidad.

Una muestra de esta modalidad de trabajo resulta de la producción de historiadores como Isabella Cosse, en quien predomina el interés por las mujeres, la familia y las relaciones de género a partir de los años sesenta. Sus corpus son muy variados, con la inclusión de cartas de lectores, manuales de comportamiento, películas, programas de radio y televisión, leyes, debates legislativos, libros, artículos científicos y entrevistas orales. ${ }^{36}$ En estos casos, predomina la estrategia analítica de multiplicar los puntos de apoyo antes que cimentar los supuestos sobre una única fuente; para ello, distintos tipos de testimonios son utilizados de manera equivalente, semejante y alternativa.

Desde una lógica similar, se desarrollan la mayoría de los trabajos dedicados a la historia reciente que integran las fuentes orales con un estatuto semejante al de las fuentes escritas. Como expresión de ello, Silvia Simonassi analiza las relaciones obrero-patronales en el área metalúrgica rosarina y para ello pasa revista a un conjunto muy diverso de materiales como prensa, actas sindicales, empresariales, documentación oficial y entrevistas a los protagonistas. ${ }^{37}$ Asimismo, Santiago Garaño, al analizar la experiencia de la prisión política, expresa la necesidad de realizar:

[...] un permanente contrapunto entre los documentos producidos por las burocracias estatales y los generados por las ex presas y presos políticos, sus familiares y el movimiento de derechos humanos durante su detención, así como las entrevistas realizadas por el autor y testimonios públicos y denuncias judiciales producidos en la posdictadura. ${ }^{38}$

\footnotetext{
${ }^{36}$ Isabella Cosse, "Probando la libertad: cambios y continuidades en el cortejo y el noviazgo entre los jóvenes porteños (1950-1970)”, Entrepasados, 33 (2008): 31-47; e Id., “Del matrimonio a la pareja: continuidades y rupturas en el modelo conyugal en Buenos Aires (1960-1975)”, Anuario IEHS, 23 (2008): 431-58.

37 Silvia Simonassi, "Conflictividad laboral y políticas disciplinarias en la industria metalúrgica de la ciudad de Rosario, 1973-1976”, Anuario IEHS, 22 (2007): 465-86.

38 Santiago Garaño, "Los pabellones de la muerte de la Unidad 9 de La Plata. Los límites difusos entre la represión legal y la clandestina”, Entrepasados, 34 (2008): 33-53 (34).
} 
Como afirmamos previamente, a la incorporación de nuevos registros históricos subyace una preocupación más sistemática por la textura subjetiva de la experiencia humana. La particularidad de estos materiales propicia que no sean considerados solo como un simple registro de la experiencia humana. Son esto último y algo más. Estas evidencias plasman las modalidades en que el mundo ha sido experimentado y llaman a superar su uso meramente informativo, restringiendo su utilización a la extracción de datos. Esto no implica eliminar la potencialidad de estas fuentes para explorar dimensiones más amplias de la vida social, sino a promover usos más variados y aproximaciones complementarias. De tal modo, la síntesis de las dos estrategias de investigación analizadas, la fuente-evento y el abordaje plural de fuentes, resumen mejor las posibilidades analíticas de este tipo de materiales. Los que no solo proporcionan una variedad y multiplicidad de datos que permiten revisar, complejizar y/o matizar las aseveraciones contenidas en muchas investigaciones, sino también habilitar nuevas vías de acceso a aspectos de la vida social poco iluminados por las fuentes tradicionales, como la subjetividad humana, la construcción y circulación de las representaciones sociales y las disputas que existen por las estructuras de poder.

Las tendencias relevadas y presentadas aquí son una aproximación muy esquemática de algunas prácticas metodológicas. No obstante, creemos que pueden resultar útiles para reflexionar sobre la instancia heurística y sus consecuencias interpretativas a la hora de investigar a partir de fuentes orales, audiovisuales o judiciales. El desafío probablemente sea el de integrar todos esos materiales en esquemas analíticos más complejos que permitan elaborar un conocimiento provisional, pero sólido y generalizable.

\section{Por un aprendizaje de nuevas prácticas}

Las novedades heurísticas de las últimas décadas se han introducido en el campo historiográfico argentino de manera gradual y en gran medida restringida a ciertos campos de estudios. Quienes integran evidencias audiovisuales, orales y judiciales en sus investigaciones son todavía muy pocos. Una verdadera minoría, si exceptuamos a quienes trabajan en determinados campos de estudios en el que esos materiales son verdaderos objetos de estudio, como los estudios visuales o la historia del crimen y el castigo. Esos materiales en general son adoptados más como interrogantes en sí mismos que como evidencias capaces de ocupar un lugar semejante al de otras tipologías más tradicionales. No pierden en esos términos su carácter no convencional. Siguen sin lograr ser exorcizadas de su excepcionalidad.

Distintas cuestiones pueden estar en la base de esta situación. Por una parte, es posible reconocer que en países como Argentina todavía existe, no solo una escasa práctica historiográfica de consulta de este tipo de materiales, sino también poco interés en asegurar adecuadas condiciones de conservación de los mismos. En un contexto institucional de escasa inversión de recursos en repositorios y valoración de los conocimientos archivísticos, solo existe una incipiente preocupación por la conservación y la puesta en consulta sistemática de este tipo de materiales. Esto último significa que quienes están 
interesados por los testimonios orales y audiovisuales en general deben llevar a cabo una tarea más que detectivesca en pos de construir sus corpus.

También es posible reconocer que, a pesar de las numerosas discusiones historiográficas generadas alrededor de estos materiales, existe todavía una incipiente maduración de consensos en torno a los protocolos de crítica y tratamiento de este tipo de materiales. Existe poca sistematización en los criterios a aplicar a la hora de evaluar la autenticidad, la intencionalidad y las posibilidades de interpretación de estos materiales. Los problemas de la memoria, la especificidad de la cultura visual y la inmanencia de las estructura de poder en todo interrogatorio siguen siendo objetos de discusiones epistemológicas significativas, que desalientan a muchos practicantes de la disciplina.

Finalmente, la poca práctica disciplinar en la utilización de estos materiales creemos que está bastante relacionada con las restricciones existentes en el aprendizaje de las herramientas específicas para su recolección y análisis. Las imágenes, los testimonios orales y las fuentes judiciales remiten cada una a una serie compleja de códigos que resulta necesario conocer a la hora de trabajar con las mismas, y quienes logran manejar estos códigos de forma competente todavía son un grupo minoritario entre los investigadores argentinos. La escasa familiaridad de los historiadores nacionales con este tipo de evidencia, está en buena medida ligada al reducido espacio de estos saberes en los planes de estudio y en el carácter hegemónico que aún mantienen los documentos oficiales y la prensa.

En definitiva, solo la mejora de las condiciones de disponibilidad de este tipo de evidencia, de la posibilidad de contar con acuerdos epistemológicos sobre su estatuto y de la provisión de aprendizajes más sistemáticos respecto de las herramientas necesarias para su selección, recolección y análisis, favorecerá usos más recurrentes y rigurosos de esos materiales. En otras palabras, estos cambios propiciarán que el reducido grupo de entusiastas historiadores familiarizados con estas fuentes formen un colectivo más extenso.

\section{Profile}

María José Ortiz Bergia es Doctora en Historia por la Universidad Nacional de Córdoba donde se desempeña como docente. Es Investigadora Asistente del Consejo Nacional de Investigaciones Científicas y Técnicas con puesto en el Instituto de Estudios Históricos. Es miembro del Centro de Estudios Históricos “Prof. Carlos S. A. Segreti” y autora de dos libros sobre historia argentina y de varios artículos sobre historia social en revistas nacionales e internacionales.

María José Ortiz Bergia has a PhD in History from the Universidad Nacional de Córdoba, where she teaches currently. She works at the Consejo Nacional de Investigaciones Científicas y Técnicas with a position of Assistant Researcher in the Intituto de Estudios Históricos. She is also a member of the Centro de Estudios Históricos "Prof. Carlos S. A. 
Segreti”, and author of two books of Argentinian history and several papers on social history published in national and international journals.

Fecha de recepción: 19 de abril de 2017.

Fecha de aceptación: 28 de noviembre de 2017.

Publicación: 31 de diciembre de 2017. 